Lifestyle Interventions to Reduce Obesity and Diabetes

Todd Alan Hagobian and Suzanne Phelan 
Todd Alan Hagobian, PhD, and Suzanne Phelan, PhD

\section{Lifestyle Interventions to Reduce Obesity and Diabetes}

\begin{abstract}
The majority of US adults are overweight or obese, which is a primary risk factor for type 2 diabetes and other chronic diseases. Recent advances in behavioral treatment of obesity have produced significant short-and longterm weight losses that reduce the risk of type 2 diabetes and cardiovascular disease. This article reviews key components of effective behavioral treatment interventions, including diet, exercise, and behavioral and psychosocial strategies. The authors review newer treatment modalities that may enhance dissemination (Internet, smartphone) and discuss applications to clinical practice. Practitioners face multiple barriers to effectively delivering lifestyle interventions in today's health care setting but, nonetheless, remain powerful motivators in belping patients initiate and maintain weight loss efforts that reduce the risk of type 2 diabetes and other chronic diseases.
\end{abstract}

Keywords: weight loss; physical activity; diet; lifestyle

\section{Introduction}

Obesity and type 2 diabetes are common, chronic disorders with major public health implications. Obesity affects approximately $33 \%$ of the adult US population $^{1-3}$ and is a primary risk factor for cardiovascular disease (CVD), hypertension, insulin resistance, and dyslipidemia (high triglycerides, high LDL cholesterol, and low HDL cholesterol). ${ }^{4-6}$ Type 2 diabetes is a similarly prevalent disorder, affecting an estimated 25 million American adults (6.8\% of population) and another 79 million who have prediabetes, or impaired fasting glucose. ${ }^{7}$ Type 2 diabetes is a known risk factor for CVD, stroke, and all-cause mortality as well as lower-limb amputations, kidney failure, and cognitive dysfunction and dementia. ${ }^{8}$
BMI $>40 \mathrm{~kg} / \mathrm{m}^{2}$ ), compared with normal weight adults, fair much worse and have up to a 7 times higher prevalence of type 2 diabetes. ${ }^{3,12}$ Gradual weight gain leading to obesity also increases the risk for developing type 2 diabetes ${ }^{5}$ because for each 1 kilogram increase in weight there is an approximate $9 \%$ increase in the relative risk for diabetes. ${ }^{13}$

Overweight and obese individuals with diabetes who attempt weight reduction face considerable challenges. However, new advances in behavioral treatment of obesity have enabled significant shortand long-term weight losses that appear to lower the risk of developing type 2

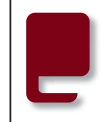

\section{Lifestyle intervention treatment "packages" have been evaluated in several clinical trials and have shown positive long-term results on health outcomes.}

It is well accepted that obesity is related to the development of type 2 diabetes. ${ }^{1,9-11}$ Obese adults, relative to those of normal weight, have a 3 times higher prevalence of type 2 diabetes, ${ }^{3,12}$ Morbidly obese adults (obesity class 3; diabetes and can result in improved glycemic control and CVD risk factors in individuals with diabetes. ${ }^{14-16}$ This article reviews the key components of effective behavioral weight control interventions that may reduce diabetes risk 
factors and improve complications of type 2 diabetes. We review the components of successful short- and long-term intervention approaches that target diet, exercise, and behavioral changes in adults. We will conclude with newer modalities (eg, online interventions) that may further enhance the dissemination and effectiveness of long-term weight control interventions. Although pharmacological interventions and bariatric surgery are effective at decreasing body weight and lowering the risk for type 2 diabetes, ${ }^{17,18}$ we focus our review on nonpharmacological and nonbariatric lifestyle intervention approaches. Moreover, because obesity and development of type 2 diabetes are significant concerns for children, we refer the reader to several recent, excellent reviews on the topic of pediatric weight control. ${ }^{19-22}$

\section{Benefits of Weight Loss}

Weight loss clearly has beneficial effects on reducing several CVD risk factors, including, but not limited to, lowering blood pressure, triglycerides, and total and LDL cholesterol and increasing HDL cholesterol. ${ }^{6,12,15,23,24}$ Weight loss has also been associated with a significant reduction in the prevalence of abdominal obesity, ${ }^{25}$ sleep apnea, ${ }^{26}$ and urinary incontinence. ${ }^{27}$ There are also positive effects of weight loss on psychosocial variables, including reductions in depression and anxiety ${ }^{28,29}$ and improvements in body image. ${ }^{30}$

Notably, weight loss also has several established benefits on development and management of type 2 diabetes. Several large randomized controlled trials (see below for more detail) have demonstrated convincingly that lifestyle intervention with a modest amount of weight loss (5\%-7\%) reduces the incidence of type 2 diabetes. ${ }^{14,31}$ Moreover, dietary changes, physical activity, and their combination can result in improved glycemic control and CVD risk factors in individuals with preexisting diabetes. ${ }^{14}$ Weight loss increases insulin action, improves glucose control, decreases fasting glucose and insulin concentrations, and lowers the dose of diabetes medication. ${ }^{14,16,32-34}$
Thus, weight loss is highly recommended for overweight (BMI $=25.0$ $\left.29.9 \mathrm{~kg} / \mathrm{m}^{2}\right)$ and obese $(\mathrm{BMI} \geq 30 \mathrm{~kg} /$ $\mathrm{m}^{2}$ ) adults at risk for type 2 diabetes or adults with type 2 diabetes. ${ }^{35}$ Although larger weight losses produce greater benefits in blood glucose, ${ }^{34,36}$ small weight losses of $5 \%$ to $10 \%$ in even very overweight persons will produce significant improvement in diabetes-related health parameters and CVD risk factors ${ }^{14-16}$ and is achievable and obtainable for most adults through lifestyle interventions. In general, glucose concentrations and other health outcomes improve with reduced energy intake before appreciable weight loss occurs, but long-term weight loss seems to further enhance glucose and diabetes health parameters. ${ }^{14,37}$

\section{Key Components of Effective Lifestyle Interventions}

Lifestyle intervention treatment "packages" have been evaluated in several clinical trials and have shown positive long-term results on health outcomes. ${ }^{31,38-41}$ Most programs achieve average weight loss of 7 to $10 \mathrm{~kg}$ (7\%$10 \%$ of initial body weight) at 6 monthsmost of which is maintained through 12 months. ${ }^{42}$ Longer-term behavior trials, such as the Diabetes Prevention Program (DPP) $)^{31}$ and the Look AHEAD (Action for Health in Diabetes) trial, ${ }^{43}$ have found clinically significant weight losses averaging $4 \%$ to $5 \%$ (or $4-5 \mathrm{~kg}$ ) at 3- to 4-year follow-ups. Although it is difficult to tease apart the precise components that contribute to success, research has identified some of the more salient features of lifestyle intervention programs, including dietary, physical activity, behavioral, and psychosocial strategies (Table 1).

\section{Dietary Prescriptions}

Patients in behavioral weight loss programs are given calorie and fat gram goals designed to produce a weight loss of about $2 \mathrm{lb}$ per week. The dietary prescriptions used have been derived from a large number of research studies comparing different degrees of caloric restriction and different macronutrient distributions. ${ }^{44,45}$ Typically, programs use calorie goals of 1200 to $1800 \mathrm{kcal} / \mathrm{d}$, with the higher goal reserved for individuals who weigh more than 200 lb. Very-lowcalorie diets (VLCDs) with $<800 \mathrm{kcal} / \mathrm{d}$ were once popular and shown to produce weight losses of approximately 20 lb in 12 weeks. ${ }^{46}$ However, weight regain often occurred when foods were reintroduced into the diet, and in the long term, patients treated with programs that combined behavior modification with VLCDs had weight loss comparable with those achieved in behavioral programs with balanced 1000- to 1800-kcal/d diets throughout. ${ }^{47,48}$ Thus, the field today has moved away from the VLCD regimens and now prescribes balanced deficit diets of 1200 to $1800 \mathrm{kcal} / \mathrm{d}$.

The fat goal is typically $30 \%$ of calories from fat and is usually prescribed to patients in grams per day to facilitate self-monitoring. A focus on reducing dietary fat consumption is partly because of the evidence that overweight individuals ${ }^{49,50}$ and individuals with type 2 diabetes $^{51}$ have higher consumption of fat. Moreover, fat is more energy dense compared with other macronutrients (ie, fat has $9 \mathrm{kcal} / \mathrm{g}$, and carbohydrate and protein have only $4 \mathrm{kcal} / \mathrm{g}$ ). Several studies $^{44,45}$ have found better weight losses when patients were given both calorie and fat gram goals than either goal alone. Thus, most behavioral treatment programs focus on reducing both calorie and fat intake.

Limiting carbohydrates (rather than fat) may also promote weight loss. Several studies have been conducted comparing low-carbohydrate diets (such as the Atkins diet) with low-fat regimens. ${ }^{52-56}$ One study included a significant proportion of patients with type 2 diabetes. ${ }^{56}$ In general, the long-term results from these studies indicate similar weight losses between the different types of regimens (ie, low fat vs low carbohydrate). For example, results of a 2-year study, in which 307 obese participants who were randomly assigned to a low-carbohydrate or a low-fat diet, indicated weight losses of $11 \mathrm{~kg}(11 \%)$ at 1 year and $7 \mathrm{~kg}(7 \%)$ at 2 years, which did not significantly differ between the 2 dietary regimens. ${ }^{52}$ What 
Table 1.

Variables Associated With Successful Weight Control.

\begin{tabular}{|l|l|}
\hline Dietary & $\begin{array}{l}\text { Low-calorie, low-fat diet } \\
\text { Meal replacements/Structured meal plan }\end{array}$ \\
\hline Physical activity & $\begin{array}{l}\text { High physical activity goals }(60-90 \mathrm{~min} / \mathrm{d}) \\
\text { Short }(\sim 10 \text { minute) bouts of physical activity } \\
\text { Exercise equipment in the home }\end{array}$ \\
\hline Behavioral & $\begin{array}{l}\text { Daily self-weighing of body weight } \\
\text { Daily monitoring of food intake } \\
\text { Goal setting } \\
\text { Stimulus control }\end{array}$ \\
\hline Psychosocial & $\begin{array}{l}\text { Social support } \\
\text { Relapse prevention/Cognitive strategies }\end{array}$ \\
\hline $\begin{array}{l}\text { Continued patient-provider } \\
\text { contact }\end{array}$ & Monthly or more frequent visits \\
\hline
\end{tabular}

appears to affect weight loss in these studies is not the macronutrient distribution but rather the level of adherence to the regimen (and ultimately the number of calories that are consumed). Although weight losses achieved with very different macronutrient diets appear to be similar, those participants who are most adherent to any of the diets lose the most weight..$^{57}$

\section{Promoting adberence to dietary} prescriptions. Rather than simply telling patients to eat 1200 to 1800 $\mathrm{cal} / \mathrm{d}$, researchers have shown that incorporating frozen entrées or liquid formulas for some of the meals may help improve adherence to the calorie goals and consequently improve weight loss outcomes. Typical meal replacement programs fix the intake of 1 or 2 meals per day with a calorie-controlled, nutritionally balanced liquid shake and allow self-selected additional meals and snacks. In obese patients, diets with meal replacements have proven to be more effective than conventional diets. Wadden and Frey $^{58}$ used a balanced deficit diet that consisted of 4 servings daily of liquid meal replacement (150 kcal each) and a prepackaged dinner entrée (about $300 \mathrm{kcal}$ ) with salad. Those using this diet as part of an intensive behavioral program lost $14.5 \mathrm{~kg}$ after 17 weeks and maintained the weight loss at 1 year. In another study of overweight patients, those on the meal replacement regimen lost $7.3 \%$ after 3 months and $8.4 \%$ after 4 years, whereas the patients on the conventional diet had lost $1.4 \%$ and $3.2 \%$ at the same respective time points. ${ }^{59}$ Meal replacements also offer a promising strategy for treating obese patients with type 2 diabetes. In one study of overweight patients with type 2 diabetes, patients in the meal replacement group achieved average weight losses of $5.2 \%$ at 6 months and $4.4 \%$ at 12 months, respectively, compared with $2.9 \%$ and $2.4 \%$ weight losses among patients prescribed an individualized dietary plan. ${ }^{59}$ The ongoing Look AHEAD trial of 5145 individuals with type 2 diabetes has also incorporated meal replacements into the dietary plan and achieved clinically significant, long-term weight losses through 4 years of follow-up.

More structured regimens appear to facilitate greater weight losses by changing the types of food stored in the home, creating a more regular pattern of meal eating, reducing difficulty with estimating portion size and planning meals, and helping control eating when not hungry. ${ }^{60,61}$

\section{Physical Activity}

Regular physical activity generally results in modest, if any, initial weight $\operatorname{loss}^{62-66}$ but is critical in maintaining weight loss and preventing weight regain. ${ }^{67,68}$ Randomized studies evaluating diet alone (restricting food intake), exercise alone, and the combination of diet and exercise have consistently shown that combining diet and exercise results in the most weight loss. ${ }^{63}$ Exercise $(\sim 60 \mathrm{~min} / \mathrm{d})$ is also the best predictor of weight loss maintenance. ${ }^{62,68}$ Independent of weight control, physical activity has several additional important health benefits; it increases cardiorespiratory fitness, ${ }^{69,70}$ increases insulin action, ${ }^{71,72}$ improves glucose control, ${ }^{14,16}$ and is related to a decreased risk for type 2 diabetes. ${ }^{73,74}$ Furthermore, exercise decreases the risk for $\mathrm{CVD}^{75}$ and promotes a favorable lipid panel (lower triglycerides, total cholesterol, and LDL cholesterol and higher HDL). ${ }^{76}$

Physical activity recommendations differ depending on the goals of an individual patient (eg, to lose weight, to prevent CVD risk factors, or prevent weight regain). In 2008, the Physical Activity Guidelines Advisory Committee Report recommended that adults participate in 30 minutes per day, 5 days per week of moderate-intensity aerobic exercise (eg, brisk walking) to reduce the risk for CVD and other metabolic diseases. ${ }^{77}$ This physical activity recommendation is corroborated by other health organizations, including the American College of Sports Medicine (ACSM), the American Diabetes Association (ADA), the American Heart Association, and the World Health Organization. ${ }^{62,78-80}$ However, this dose of exercise (ie, $30 \mathrm{~min} / \mathrm{d}, 5 \mathrm{~d} / \mathrm{wk}$ or $150 \mathrm{~min} / \mathrm{wk}$ ) is recommended to reduce the risk for disease and is likely insufficient to lose weight or maintain weight loss. The Institute of Medicine ${ }^{67}$ currently recommends $60 \mathrm{~min} / \mathrm{d}$ every day of the week to maintain a healthy BMI and 60 to $90 \mathrm{~min} / \mathrm{d}$ to promote weight loss maintenance.

Brisk walking is the most common type of exercise and is typically recommended in behavioral interventions and by public health guidelines. ${ }^{62,67,78-80}$ Some public 
health organizations recommend strength training in addition to walking (ADA, ACSM). For example, the ACSM developed the first public health guideline for adults to participate in regular strength training (ie, lifting weights). ${ }^{79,80}$ Even though adding strength training to an aerobic exercise program may not result in greater weight loss, ${ }^{81}$ strength training increases blood flow to active muscle, ${ }^{82}$ insulin action, ${ }^{82}$ and muscular strength ${ }^{79,80}$ and is a necessary component of a physical activity program.

For promoting weight loss and maintenance, many randomized studies have shown that higher doses of exercise result in the best outcomes. Jakicic et al ${ }^{83}$ found that women in a behavioral intervention reporting higher amounts of physical activity (ie, >200 min/wk) had greater weight losses at 6, 12, and 18 months compared with women with $\leq 150$ $\mathrm{min} /$ wk of exercise $(-13.1 \mathrm{~kg}$ vs $-3.5 \mathrm{~kg}$, respectively). Similarly, Jeffery et $\mathrm{al}^{84}$ randomly assigned 202 overweight adults to a behavioral intervention focused on a 1000 or $2500 \mathrm{kcal} /$ wk exercise goal. The $2500 \mathrm{kcal} /$ wk exercise group, relative to the $1000 \mathrm{kcal} /$ wk group, reported significantly higher exercise levels and greater weight losses at $12(-8.5 \mathrm{~kg}$ vs $6.1 \mathrm{~kg}$, respectively) and 18 (-6.7 kg vs $4.1 \mathrm{~kg}$, respectively) months. However, after the intervention stopped at 18 months, activity declined in the higher exercise goal group, and there was no difference between groups in exercise and body weight loss at 30 months. ${ }^{85}$ Thus, there may be more barriers to exercise with higher doses, and continuing to participate in a behavioral intervention may be necessary to maintain higher amounts of exercise.

Promoting adherence to exercise goals. Higher levels of physical activity are related to better long-term weight loss outcomes, so the question becomes, "How best to encourage overweight individuals to adopt and maintain a higher level of physical activity?" One approach may be to encourage more flexible exercise routines. Jakicic et a ${ }^{86}$ conducted a study in which all women received the same diet, the same behavioral program, and the same exercise goals. However, a long-bout group did their exercise in one 40-minute bout, whereas a shortbout group was instructed to exercise in four 10-minute bouts. The short bout exercise prescription led to better exercise adherence; these participants were more likely to exercise on any given day and completed more minutes of exercise over the course of the program. Their weight losses were also somewhat better. Interestingly, the short- and long-bout groups had comparable improvements in cardiovascular fitness. Accumulating multiple daily short bouts of exercise (10 minutes, 3 times/d) may be easier for obese adults to achieve and result in long-term exercise adherence. ${ }^{83}$

Another way to improve exercise adherence is to modify the environmental cues for physical activity. Cross-sectional and descriptive studies suggest that exercise levels are higher when exercise equipment is in the home. ${ }^{87,88}$ Similarly, Jakicic et $a l^{83}$ showed that overweight women randomly assigned to exercise with home exercise equipment (vs exercise without home exercise equipment) showed higher exercise adherence and experienced greater weight and body fat loss. Taken together, these data suggest that having exercise equipment in the home may be a convenient way for individuals to accumulate multiple bouts of exercise and meet current physical activity recommendations.

Home-based exercise programs also appear to promote better adherence than supervised exercise in a controlled laboratory setting. ${ }^{83,89}$ Perri et al ${ }^{89}$ found that in obese women after 12 months, homebased exercise increased exercise participation and adherence compared with supervised exercise. Also, in obese women, 12-month weight losses were greater with home-based exercise relative to supervised exercise (11.6 vs $7.0 \mathrm{~kg}$, respectively).

\section{Behavioral Strategies}

Behavioral strategies typically include a combination of goal setting, selfmonitoring with feedback, stimulus control, and relapse prevention/problem solving, ${ }^{39,40}$ as described below.
Self-monitoring. Self-monitoring of diet is often considered the single most important component of a behavioral weight control program..$^{90,91}$ Patients are taught to write down everything they eat, to estimate or count calories in those foods by reading food labels or using a resource, and to record a running total of their calorie intake to ensure they stay within their calorie goal. Patients also write down each type of exercise, including minutes of time spent exercising and the number of steps taken each day, as tracked by a pedometer. The patient is then taught to use the diary to evaluate their current behavior, identify problems, and select specific behaviors to target for change. Interventionists review food and activity records and provide specific guidance on choices and supportive feedback to the patient. ${ }^{39,40}$ A number of clinical trials have found self-monitoring to be significantly correlated with shortand long-term weight loss outcomes. ${ }^{91,92}$ Participants are also given a weight goal and told to weigh themselves and to track progress toward their goal on a weight graph. Several studies have now shown that frequent self-weighing is a significant and independent predictor of weight loss, less weight regain, and avoidance of initial weight gain in adults. ${ }^{93,94}$ Daily self-weighing appears to promote the best weight control when combined with behavioral treatment programs. ${ }^{93,95,96}$ Of note, frequent selfweighing is not associated with an increase in adverse psychological outcomes, including depressive symptoms, eating disorders, or binge eating. ${ }^{97}$

Although adherence to self-monitoring tends to wane over time, ${ }^{98}$ the advent of new technologies, such as the Internet, PDAs, and smartphones, may make the task of self-monitoring easier for patients. Patients are able to look up the calories in a database and save the data to an online record. Similarly, a variety of instruments are now available that can provide objective measures of physical activity. These instruments may not only make self-monitoring easier but also provide a way for interventionists to monitor patients' behaviors in real time and provide helpful guidance and support. ${ }^{99}$ 
Goal setting. Typically, in behavioral weight loss programs, participants are given goals for calorie and fat, and physical activity, and asked to monitor and modify these aspects of their behavior. Although the overall behavioral goals are quite general (eg, eat $1500 \mathrm{kcal} / \mathrm{d}$, $<30 \%$ from fat, and exercise $200 \mathrm{~min} /$ wk), more specific daily goals (eg, use jam instead of butter on bread) help break the behavior change into small, achievable steps rather than a general goal, such as to eat less fat.

Stimulus control. Given the role of environmental factors in influencing weight, lifestyle programs typically teach stimulus control techniques to reduce the cues for inappropriate behaviors and strengthen the cues for appropriate eating and activity. Stimulus control techniques are designed to reorganize the environment to support desired behaviors. Patients are taught that it is difficult to consistently make good eating and exercise choices in an environment that does not support these behaviors. Thus, they are instructed to reduce or eliminate cues that encourage overeating/ inactivity (eg, remove chips, desserts, or other tempting foods from the house and reduce the number of TVs in the home) and to make it as easy as possible to make good choices (eg, leave exercise equipment in a highly visible area and have low-fat snacks readily available in the refrigerator).

\section{Psychosocial Strategies}

Cognitive techniques. Cognitive therapy, when combined with diet and exercise interventions, produces superior weight losses than diet and exercise treatment alone. ${ }^{38}$ Thus, the cognitive component is often added to effective treatment packages. Cognitive approaches to weight loss focus on identifying and modifying maladaptive thoughts or selfperceptions associated with overeating and inactivity, prior relapses, or prior treatment failures. Patients are taught to identify and change the maladaptive thoughts and emotions that can contribute to overeating and inactivity, including dichotomous thinking (eg, "If I can't eat healthy at every meal, I might as well not do it at all") and rationalizations (eg, "I've had a hard day, I deserve a piece of cake"). Patients are taught to replace these negative thoughts with more positive and helpful self-statements.

Relapse prevention. Based on Marlett and Gordon's relapse prevention model, ${ }^{100}$ patients are taught to identify specific situations that might pose problems for dietary or exercise adherence. Three common types of high-risk situations are situations involving food cues (eg, being in a restaurant or a family meal), situations involving affective cues (eg, anger and depression), and situations involving boredom or transition (eg, watching TV). Patients are taught to use behavioral coping strategies (such as leaving the room) and cognitive coping responses (devaluing the food) to prevent lapses from turning into relapses. Similarly, they are taught to use problem-solving techniques to overcome these and other barriers to their desired goals. ${ }^{101}$

Providing participants with training in relapse prevention and with continued therapist contact improves long-term weight maintenance. ${ }^{102}$ Relapse prevention training was provided to 1 group during the last 6 weeks of the treatment program; these participants were taught about the process of relapse and practiced skills needed to identify and cope with high-risk situations and to recover from acute lapses. The group that received both relapse-prevention training and continued therapist contact had significantly better weight maintenance than any other group. ${ }^{102}$

Social support. Social support has long been studied as a way to improve motivation for long-term weight loss. Overall, findings on the effects of social support suggest a small positive effect. ${ }^{103}$ Wing and Jeffery ${ }^{104}$ examined the effects of recruiting patients with friends and providing a social support-focused treatment; the best weight losses were found in those individuals who were recruited with friends and provided with the social support intervention. However, other studies have shown more mixed results for social support. A meta-analysis of 21 articles examined the role of family support in weight loss and found inconclusive results; yet spouse involvement appeared to increase effectiveness. ${ }^{105}$ Interestingly, Gorin and colleagues $^{106}$ showed that there is a ripple effect of participating in a weight loss program; not only do participants in a weight loss program lose weight, but their spouses do too, even though they do not attend meetings. Moreover, the greater the weight loss of the participant, the greater the weight loss in the spouse. Based on findings such as this, a common treatment strategy has been to ask spouses to actually participate in the weight loss program along with the participant and to make the same changes in eating and exercise behavior. Overall, support from social context is often helpful but can, for some patients, interfere with long-term weight management.

\section{Ongoing Patient-Provider Contact}

Contact with a practitioner appears to be the most effective approach to helping patients maintain their behavior changes. Several studies have shown the benefits of continuing to attend weight control classes in the long term. ${ }^{48,101,107,108}$ Continued contact (typically weekly for 6 months and every 2 weeks or monthly thereafter) seems to provide patients with the support and motivation needed to continue to practice weight control behaviors, such as diet monitoring and exercising regularly. The nature of contact (ie, individual vs group meetings) appears to be less important than continuing to see patients, but one randomized controlled trial found that group treatment induced a significantly larger weight loss than individual care, even in patients who indicated a preference for and received individual treatment. ${ }^{109}$

\section{Lifestyle Intervention Trials: Long-term Results}

As noted earlier, several large, randomized controlled trials have now documented the long-term outcomes of 
comprehensive lifestyle intervention programs on weight loss, diabetes, and CVD outcomes. The 3 largest randomized controlled trials are the US DPP ${ }^{14}$ the Finnish Diabetes Prevention Study (DPS), and the Look AHEAD trial. ${ }^{16,32,110}$ All studies included a comprehensive behavioral weight loss program, as described above.

The US DPP ${ }^{14}$ is the largest randomized trial to examine whether a comprehensive lifestyle intervention could prevent the progression of prediabetes to diabetes in 3234 overweight/obese individuals with prediabetes with impaired glucose tolerance. Participants were randomly assigned to lifestyle intervention, metformin (most commonly prescribed antidiabetes medication), or placebo (control) groups. The goals for the lifestyle group were to lose $\geq 7 \%$ of body weight by eating a low-calorie (1200-1800 kcal/d), low-fat $(<30 \%)$ diet and exercising $>150$ minutes per week. In the lifestyle group, the behavioral intervention included 16 lesson plans incorporating diet, exercise, and behavioral modification to achieve group goals. Study interventionists met with participants weekly during the initial 24 weeks and at least bimonthly for the next 4 years. The metformin group received a dose of $850 \mathrm{mg}$ twice daily plus a standard lifestyle care recommendation. The placebo group received a standard care lifestyle recommendation. Mean body weight loss was greater in the lifestyle group relative to the metformin and placebo groups $(-5.6,-2.1$, and -0.1 $\mathrm{kg}$, respectively).

The DPP intervention was extremely effective in reducing the risk of diabetes. The crude incidence of diabetes was 11.0, 7.8, and 4.8 cases per 100 person yeas for placebo, metformin, and lifestyle, respectively. Thus, lifestyle intervention reduced the risk of diabetes by $58 \%$ compared with placebo and by 39\% compared with metformin (Figure 1). Weight loss was the best predictor of a lower incidence of diabetes. ${ }^{111}$ Furthermore, with every kilogram of weight lost, there was a $16 \%$ reduction in risk for diabetes. ${ }^{111}$ Those who met all lifestyle intervention goals had an $89 \%$ reduced risk of diabetes. Finally, those who met physical activity goals without meeting the weight loss

Figure 1.

Incidence of diabetes in the placebo, metformin, and lifestyle intervention group after 4 years in the US Diabetes Prevention Program. Lifestyle intervention reduced the incidence of diabetes by $58 \%$ and $39 \%$ compared with placebo and metformin, respectively (reprinted from Knowler et al ${ }^{14}$; used with permission).

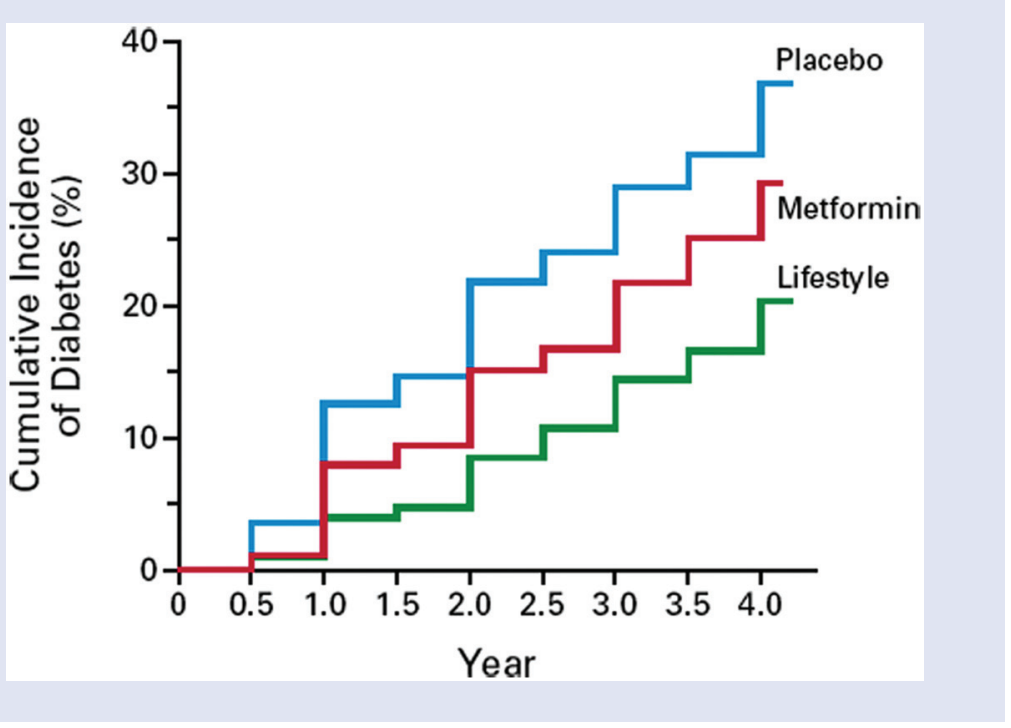

goal (>7\%) decreased the risk of diabetes by $46 \%$.

In the Finnish DPS ${ }^{16,32} 522$ overweight men and women with impaired glucose tolerance were randomly assigned to a lifestyle intervention or control group. The behavioral goals of the lifestyle group were to lose $\geq 5 \%$ of body weight, reduce fat intake to $<30 \%$ of total food intake, and exercise for $\geq 30 \mathrm{~min} / \mathrm{d}$. Those in the lifestyle group were given guidance on how to accomplish these goals and had a visit with a nutritionist 7 times during the first year and 4 times each year after that. Guidance was individually tailored to each participant throughout the intervention. The control group received general information about lifestyle modifications to reduce the risk for type 2 diabetes at the start of the study alone. In the lifestyle group compared with controls, after 1 year, $43 \%$ versus $13 \%$ of participants reduced body weight by $>5 \%, 47 \%$ versus $26 \%$ reduced fat intake to $<30 \%$ of food intake, and $86 \%$ versus 71 exercised $>4 \mathrm{~h} / \mathrm{wk}$. In the lifestyle group, mean body weight loss was $4.7 \%$ after 1 year versus $0.9 \%$ in the control group. The greater weight loss in the intervention group was accompanied by significantly greater decreases in blood pressure and concentrations of glucose, insulin, and triglycerides relative to controls. Similar to the DPP, the cumulative incidence of diabetes was 58\% lower in the lifestyle intervention group compared with the control group after 6 years (Figure 2), and weight loss was the best predictor of remaining free of diabetes. Furthermore, all participants meeting at least 4 of 5 prescribed lifestyle goals remained free of diabetes.

Look AHEAD is a multicenter, ongoing randomized study evaluating whether an intensive lifestyle intervention lowers the risk for cardiovascular morbidity and mortality in 5145 overweight or obese individuals with type 2 diabetes. ${ }^{15,23,33,34,112,113}$ Overweight or obese adults (BMI $\left.>25 \mathrm{~kg} / \mathrm{m}^{2}\right)$ were randomly assigned to an intensive lifestyle intervention group or a standard care (control) group. The 2 main goals of the lifestyle intervention are for participants to lose $\geq 7 \%$ of body weight and increase physical activity to $\geq 175 \mathrm{~min} / \mathrm{wk}$ 
Figure 2.

Proportion of overweight or obese participants without diabetes after 6 years in the Finnish Diabetes Prevention Study. The risk for diabetes was reduced by $58 \%$ in the lifestyle intervention group compared with the control group (reprinted from Tuomilehto et al ${ }^{16}$; used with permission).



using a comprehensive behavioral intervention. The intervention is similar to the US DPP. Participants in the lifestyle group attended weekly behavioral meetings during the initial 6 months, 3 meetings per month from 6 to 12 months, and $\geq 1$ meeting per month from years 2 to 4 . The meetings focused on diet (including use of meal replacements), physical activity, and behavioral approaches to meet the weight loss goals. After 4 years, participants in the lifestyle group, relative to controls, had a greater percentage of weight loss $(-6.15 \%$ vs $-0.88 \%$, respectively) and greater mean change in glycated hemoglobin $\left(\mathrm{HbA}_{1 \mathrm{c}} ;-0.36 \%\right.$ vs $-0.09 \%$, respectively), systolic blood pressure $(-5.33 \%$ vs $-2.97 \%$, respectively), triglycerides ( $-25.56 \%$ vs $-19.75 \%$, respectively), HDL cholesterol (3.67\% vs $1.97 \%$, respectively), and cardiorespiratory fitness (+12.74 vs 1.96\%, respectively). Moreover, in the lifestyle group compared with controls, after 4 years,
$35 \%$ versus $18 \%$ of participants reduced weight by $\geq 7 \%$ weight, and $23 \%$ versus $10 \%$ of participants reduced weight by $\geq 10 \%$ weight (Figure 3). ${ }^{114}$ Furthermore, participants in the lifestyle intervention had lower medication use and lower costs to treat CVD risk factors. ${ }^{33}$ These data clearly show that a comprehensive behavioral intervention can promote long-term weight loss and improve CVD risk factors in overweight or obese men and women with type 2 diabetes. The ongoing intervention over the next 7 years will determine whether CVD mortality is lower in the lifestyle group. Look AHEAD has documented the beneficial effects of weight loss on glycemic control in individuals with type 2 diabetes. However, other randomized studies using less-intensive dietary interventions in individuals with or without diabetes have shown no significant improvements in $\mathrm{HbA}_{1 \mathrm{c}}$ levels with modest weight losses $(-0.8$ to $-4.6 \mathrm{~kg}) .{ }^{115-119}$ Brinkworth et $\mathrm{al}^{115}$ showed that 12 weeks of energy restriction resulted in weight loss of 5.3 $\mathrm{kg}$ and lower $\mathrm{HbA}_{1 \mathrm{c}}$ levels. At 64 weeks, the average weight loss was $-2.9 \mathrm{~kg}$, yet $\mathrm{HbA}_{1 \mathrm{c}}$ levels had increased to baseline levels. Redmon et $\mathrm{a}^{118}$ found that a dietary intervention for 2 years resulted in a weight loss of $4.6 \mathrm{~kg}$, but $\mathrm{HbA}_{1 \mathrm{c}}$ levels were not significantly lower than at baseline. These studies suggest that low-intensive lifestyle interventions may have less of an impact on glycemic control compared with more comprehensive behavioral interventions that target both diet and physical activity, as was done in Look AHEAD.

In sum, the Finnish DPS, US DPP, and Look AHEAD provide strong support that long-term comprehensive lifestyle modification can prevent or delay the progression of prediabetes to diabetes and improve type 2 diabetes and CVD risk factors. Taken together, these data suggest that (1) lifestyle modification, with a modest amount of weight loss (5\%-7\%), reduces the incidence of diabetes by up to $58 \%$; (2) weight loss is the best predictor of reduced risk for diabetes; (3) meeting prescribed lifestyle goals substantially lowers the risk for diabetes; (4) increased physical activity, with modest weight loss, independently lowers the risk for diabetes; and (5) in adults with type 2 diabetes, modest weight loss improves glycemic control, improves CVD risk factors, and decreases medication use.

\section{Long-Term Successful Weight Loss}

Even though many overweight or obese individuals are able to achieve weight loss, many regain lost weight within 2 to 5 years after treatment termination. ${ }^{120-122}$ Whether the high degree of recidivism after weight loss is a result of biological or behavioral factors remains unclear. Some investigators conclude that weight regain is inevitable as a result of strong biological pressures to return to an obese body weight. ${ }^{123}$ For example, weight loss generally alters peripheral hormones in a direction expected to stimulate food intake and promote body weight regain. ${ }^{124,125}$ Cummings et a ${ }^{124}$ observed 


\section{Figure 3.}

Percentage of participants in diabetes support and education (DSE; controls) and intensive lifestyle intervention (ILI) groups who at 4 years met different categorical weight losses in Look AHEAD. Significantly greater percentage of participants in ILI, relative to controls, met each of the categorical weight losses shown $\left(P<.0001 ;\right.$ reprinted from Wadden et al ${ }^{114} ;$ used with permission).

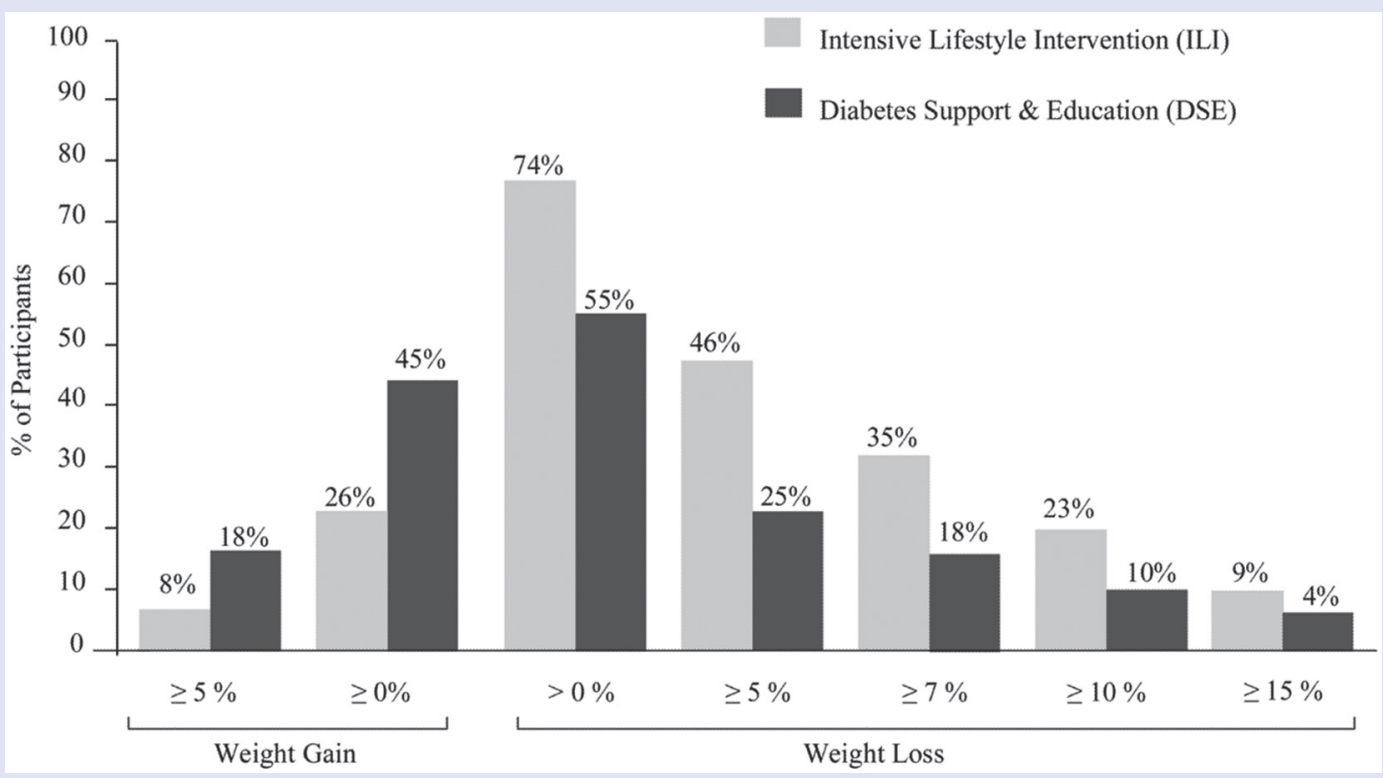

that a $17 \%$ weight loss was associated with a $24 \%$ increase in ghrelin concentrations, indicating more stimulus to eat. Sumithran et al ${ }^{125}$ found that 1 year after $14 \%$ weight loss, the hormonal response was altered (higher ghrelin, lower leptin, and insulin) in a direction expected to stimulate food intake and promote weight regain. Taken together, these data suggest that overweight or obese individuals who lose weight have a strong physiological drive to regain lost body weight. On the other hand, other researchers believe that weight regain is a result of the inability to maintain behavior changes in the long term ${ }^{126}$ or a result of environmental relapse, in which it is impossible to maintain appropriate diet and physical activity patterns within an environment that promotes energy intake and discourages physical activity. ${ }^{127}$ Clearly, there is more work to be done in this area of understanding the relative role of behavioral and metabolic factors in predicting weight gain and weight maintenance.

It is interesting to note that although there is great pessimism surrounding the issue of long-term successful weight loss, this belief does not appear to be well substantiated. In the Look AHEAD lifestyle intervention, for example, $37 \%$ lost at least $10 \%$ of their body weight at year 1 and 23\% continued to maintain a weight loss of at least $10 \%$ of their body weight at 4 years (Figure 3). Similarly, several epidemiological studies suggest that approximately 1 out of 3 overweight individuals are successful at maintaining a $5 \%$ to $10 \%$ weight loss for 1 year or more. ${ }^{128,129}$ Thus, there may be greater levels of success than is often recognized. In an effort to learn more about successful weight loss maintenance, Hill and Wing established the National Weight Control Registry (NWCR) in 1994. ${ }^{130}$ The registry enrolls individuals who are older than 18 years and who report having lost at least 30 pounds and kept it off for at least 1 year. There are currently 10000 individuals in the NWCR. Although this is not a representative sample of all successful losers, it provides a rare opportunity to examine weight loss maintenance. The registry members are $77 \%$ women,
82\% college educated, 95\% Caucasian, and $64 \%$ married; average age is 46.8 years. Participants report having lost an average of $33 \mathrm{~kg}$, reducing from a BMI of $36.7 \mathrm{~kg} / \mathrm{m}^{2}$ to $25.1 \mathrm{~kg} / \mathrm{m}^{2}$ and maintaining a weight loss of at least $30 \mathrm{lb}$ for an average of 5.7 years; $13 \%$ have maintained the weight loss for at least 10 years. Thus, by any criterion, these individuals are clearly successful.

Nearly all the NWCR members reported using both diet and physical activity to lose weight and keep it off. ${ }^{130}$ Reported calorie and fat intake were low (averaging $1380 \mathrm{kcal} / \mathrm{d}$ with $24 \%$ as fat), and exercise levels were very high (2800 kcal/ wk). These data underscore the importance of these 2 behavioral strategies for long-term weight control. The successful weight loss maintainers also reported frequent self-weighing - typically daily ${ }^{131}$ consistency in their diet across weekdays, weekends, and holidays, ${ }^{132}$ and low levels of television viewing. ${ }^{133}$ They also report a healthy home food and exercise environment with significantly more pieces of exercise equipment and healthy foods 
in visible locations in the home than an overweight control group. ${ }^{134}$ Findings from the NWCR suggest that successful weight loss maintenance is possible through hard work and dietary and exercise vigilance.

\section{Newer Treatment Modalities}

Short- and long-term behavioral interventions are clearly successful at reducing body weight. However, these interventions typically require substantial face-to-face visits, are not available to the public, and are difficult to disseminate and costly to implement. Internet-based interventions may potentially lower the costs of traditional face-to-face behavioral interventions. In one of the first randomized, short-term studies, Tate et $\mathrm{al}^{135}$ assigned 91 overweight adults to an Internet education (control) or Internet behavioral intervention group. The Internet behavioral intervention consisted of 24 weekly lesson plans via e-mail and weekly online submission of food diaries. Weight loss was significantly greater at 3 and 6 months in the Internet intervention relative to controls ( $4.1 \mathrm{~kg}$ vs $1.6 \mathrm{~kg}$, respectively), suggesting that an online behavioral approach can produce clinically significant weight loss.

Subsequent studies have compared online versus traditional face-to-face interventions. In the weight loss maintenance trial, ${ }^{136}$ participants who had lost at least $4 \mathrm{~kg}$ during the initial 6-month program were randomly assigned to either an interactive technology-based maintenance program, a personal contact intervention (monthly phone contacts and quarterly in-person sessions), or a minimal contact control. The inperson program produced the best longterm results, with no difference between the other 2 conditions. Similarly, face-toface contact was also most effective in the STOP Regain trial. ${ }^{137}$ In this trial, participants were recruited after having lost weight either on their own or through any type of program. They were then offered an 18-month self-regulation program designed to help them maintain their weight losses. The program taught participants to self-weigh daily and to use the information from the scale to determine if adjustments in diet and activity were needed. Those who were randomly assigned to receive the program through monthly face-to-face meetings had better outcomes than those who received the program via the Internet, with the poorest results in those in the control group.

Although greater weight losses are often seen in face-to-face compared with online modalities, Internet-based interventions nonetheless produce clinically significant weight losses $(>5 \%)$ that are maintained over time. ${ }^{85,99,138-142}$ Moreover, an appealing aspect of Internet interventions is the costeffectiveness relative to standard behavioral interventions. Krukowski et $\mathrm{al}^{143}$ recently found that a standard behavioral intervention with substantial face-to-face contact cost $\$ 372$ per person, whereas an Internet intervention cost $\$ 158$ per person. The main difference in cost was participant travel time, and the Internet intervention substantially lowered this burden. Thus, preliminary data suggest that Internet behavioral interventions are successful at lowering and maintaining body weight in a cost-effective manner.

Other emerging approaches to promoting weight loss and maintenance include use of text messaging and smart phone applications. Patrick and colleagues ${ }^{144}$ evaluated the efficacy of a weight loss intervention delivered via text messaging on mobile phones and found, after 4 months, that the intervention group lost more weight than the control group (2-kg difference). Other ongoing randomized studies ${ }^{145-147}$ are evaluating the effects of smart phone applications designed to alter diet and physical activity. Coons et $a l^{145}$ compared whether a smartphone weight loss system, designed to promote self-regulation and adherence, is better than a standard face-to-face behavioral intervention. Others are currently assessing whether interactive digital games and new movements (exergaming) may increase energy expenditure and promote weight loss. ${ }^{147}$ Clearly, this line of research is in its infancy but exciting for its potential to increase dissemination and, potentially, the efficacy of existing interventions.

\section{Weight Loss Counseling in the Clinic Setting}

For practitioners treating an obese patient with or without type 2 diabetes, a critical question is, "How do I incorporate these behavioral interventions into my practice?" Practitioners face multiple barriers to effectively delivering behavioral treatment, including limited coverage by insurance, limited time and training in behavioral techniques and obesity treatment, competing needs to handle co-occurring medical issues, and perceived lack of interest on the part of their patients. ${ }^{148}$ Although available data do not yet indicate how best to incorporate providers in more intensive approaches to achieve successful weight loss, ${ }^{149}$ exciting innovations are under way. ${ }^{150,151}$ Moreover, practitioner advice can have a powerful impact on a patient initiating weight loss efforts. Galuska and colleagues $^{152}$ found that physician advice to lose weight led to a 3-fold increase in patients' attempts to address their weight. Several government bodies and panels have come up with recommendations on how physicians and other practitioners can best address overweight in clinical practice. ${ }^{153-158}$ Here, we highlight the following key points:

1. In discussing weight with patients, consider the terms used to describe excess weight. Wadden and Didie ${ }^{159}$ conducted a survey of obese patients and found that patients' least desirable terms for referring to their weight included Fatness, excess fat, obesity, and large size. The more desirable terms were weight, heaviness, BMI, and excess weight.

2. Make specific calorie recommendations (eg, 1200-1800 $\mathrm{kcal} / \mathrm{d}$ ) and progressive exercise goals leading to the ultimate goal of 60 to 90 minutes of activity per day. Diet and exercise goals should be achievable, with the initial goal of modest weight loss (7\%-10\%). Also, patients should be encouraged to start monitoring daily food intake, exercise, and weight.

3. Practitioners should refer obese patients to other practitioners (eg, 
dieticians, psychologists, and exercise physiologists) or commercial weight loss programs for additional support and guidance. In a multicenter study, Heshka and colleagues ${ }^{160}$ found that participants in Weight Watchers lost $5.3 \%$ of their initial weight at 1 year and maintained a loss of $3.2 \%$ at 2 years, compared with $1.5 \%$ and $0 \%$, respectively, among those who received self-help materials. Commercial programs remain a potential avenue for supplemental help, although additional research is clearly needed in this area. ${ }^{161}$

4. Continue to meet with patients and discuss weight and behavior changes on a regular basis. Practitioners can support patients' weight loss efforts by reviewing changes in weight and health complications at regularly scheduled office visits and by monitoring patients' efforts to improve their eating and activity behaviors. ${ }^{161}$ Success in weight loss should be reinforced and praised, and setbacks should be met with empathy and with encouragement to maintain weight control efforts.

The National Institutes of Health is currently funding ongoing interventions focused on clinic-based support for patients to lose body weight. ${ }^{150,151}$ The premise behind this funding is that physicians may have a profound impact on the success of their patients' weight loss, but contact with the patient is limited and typically involves many other medical concerns or priorities. Christian and colleagues ${ }^{150,151}$ have developed a brief, computer-based program that provides feedback to patients on improving barriers to diet and physical activity. Preliminary data are encouraging because overweight adults achieved an average 1.6\% (-1.6 kg) weight loss over 12 months. Moreover, $26.3 \%$ of adults in the intervention sustained weight loss of $\geq 5 \%$. In the notso-distant future, computer and other programs similar to this one may be available to providers to help their patients lose weight and reduce the risk for chronic disease.

\section{Conclusions and Future Directions}

Comprehensive lifestyle interventions are clearly successful at promoting longterm weight control and lowering the risk for type 2 diabetes and associated complications. Modest weight losses (5\%10\%) may have a profound impact on the risk for diabetes in adults. Moving forward, there are several promising areas of investigation. Here, we highlight 3 areas.

\section{Prevention}

There are several areas to pursue for the primary prevention of obesity and type 2 diabetes. Although not the focus of this review, prevention of obesity in children has become a major area of interest. ${ }^{162}$ Obesity in childhood is associated with obesity in adulthood; the older the child, the stronger the association between childhood and adulthood weight status. Moreover, childhood obesity is associated with the same health consequences as adult obesity, including increased risk of developing type 2 diabetes. There are some promising interventions for prevention of weight gain in children and adolescents ${ }^{20}$ but new advances and more effective and disseminable programs are clearly needed. ${ }^{21}$

Given the high prevalence of obesity and type 2 diabetes in minority populations, development of effective interventions for at-risk, underserved populations is also critical. More research is needed to examine the impact of culturally adapted weight loss and weight gain prevention approaches, taking into consideration the ways in which minority populations interact with the health care system, school system, and community settings.

Finally, the time surrounding pregnancy is another understudied and potentially powerful "teachable moment" for obesity and diabetes prevention. ${ }^{163}$ Gestational diabetes (GDM) is a strong risk factor for the development of type 2 diabetes in women. An estimated 3\% to 70\% of women with GDM will develop type 2 diabetes within 15 years after the birth of their child. ${ }^{164-167}$ Women with recurrent GDM and obesity are at even greater risk of developing type 2 diabetes. ${ }^{168,169}$ Preliminary research from epidemiological and bariatric surgery studies suggests that development of GDM may be prevented by reducing prepregnancy body weight. ${ }^{170-173}$ However, future research is needed to examine the effects of lifestyle interventions before pregnancy to reduce body weight and prevent GDM. More research has been done during pregnancy, and initial findings suggests that helping women gain the recommended amount during pregnancy through healthy eating and physical activity could make a major contribution to preventing postpartum weight retention, particularly in normal weight women. ${ }^{174-176}$ However, more randomized controlled trials are needed to identify the effects of lifestyle interventions on maternal/fetal outcomes and the most effective and disemminable interventions during pregnancy, particularly for obese women.

\section{Maintenance of Long-term Weight Control}

Weight loss is clearly effective in preventing and treating a variety of health problems, including type 2 diabetes. Moreover, over the past several decades, our ability to help overweight/obese patients lose weight has significantly improved. Nonetheless, over time, there is gradual weight regain, with an average weight loss of 4 to $5 \mathrm{~kg}$ at the 3- to 4-year follow-up. Many individuals fail to maintain a $\geq 5 \%$ weight loss. It is critical that we better understand the environmental, physiological, and psychosocial variables that make it difficult to maintain weight loss in the long term and lead to this gradual regain. Efforts to overcome these barriers with new behavioral approaches may lead to better long-term outcomes.

\section{Dissemination}

Lifestyle programs can have important health benefits, but they are still not readily available to many overweight or obese individuals. Further research is needed to determine how best to disseminate these programs. As noted earlier, of particular interest is the role of technology in expanding the audience who could participate. Whether these 
programs should be covered by insurance programs is another important public health issue. Efforts are also needed to document the outcomes that participants experience in commercial weight loss programs, including both face-to-face and Internet approaches, in order to determine what role these programs can play in combating the obesity epidemic.

It is critical that practitioners continue to work with scientists and policy makers using a multidisciplinary approach to further understand how best to prevent and treat obesity and its profound health consequences, including type 2 diabetes.

\section{References}

1. Flegal KM, Carroll MD, Ogden CL, Curtin LR. Prevalence and trends in obesity among US adults, 1999-2008. JAMA. 2010;303:235-241.

2. Mokdad AH, Bowman BA, Ford ES, Vinicor F, Marks JS, Koplan JP. The continuing epidemics of obesity and diabetes in the United States. JAMA. 2001;286:1195-1200.

3. Mokdad AH, Ford ES, Bowman BA, et al. Prevalence of obesity, diabetes, and obesity-related health risk factors, 2001. JAMA. 2003;289:76-79.

4. Berenson GS. Obesity: a critical issue in preventive cardiology: the Bogalusa Heart Study. Prev Cardiol. 2005;8:234-241; quiz 242-243.

5. Colditz GA, Willett WC, Stampfer MJ, et al. Weight as a risk factor for clinical diabetes in women. Am J Epidemiol. 1990;132:501-513.

6. Maggio CA, Pi-Sunyer FX. The prevention and treatment of obesity: application to type 2 diabetes. Diabetes Care. 1997;20:1744-1766.

7. Centers for Disease Control and Prevention. National diabetes fact sheet: national estimates and general information on diabetes and prediabetes in the United States, 2011. Atlanta, GA: Department of Health and Human Services, Centers for Disease Control and Prevention; 2011.

8. Lew EA, Garfinkel L. Variations in mortality by weight among 750,000 men and women. J Chronic Dis. 1979;32:563-576.

9. Cowie CC, Rust KF, Byrd-Holt DD, et al. Prevalence of diabetes and impaired fasting glucose in adults in the U.S. population: National Health And Nutrition Examination Survey 1999-2002. Diabetes Care. 2006;29:1263-1268.

10. Harris MI, Flegal KM, Cowie CC, et al.
Prevalence of diabetes, impaired fasting glucose, and impaired glucose tolerance in U.S. adults. The Third National Health and Nutrition Examination Survey, 1988-1994. Diabetes Care. 1998;21:518-524.

11. Li C, Ford ES, Zhao G, Mokdad AH. Prevalence of pre-diabetes and its association with clustering of cardiometabolic risk factors and hyperinsulinemia among U.S. adolescents: National Health and Nutrition Examination Survey 2005-2006. Diabetes Care. 2009;32:342-347.

12. Field AE, Coakley EH, Must A, et al. Impact of overweight on the risk of developing common chronic diseases during a 10-year period. Arch Intern Med. 2001;161:1581-1586.

13. Mokdad AH, Ford ES, Bowman BA, et al. Diabetes trends in the U.S.: 1990-1998. Diabetes Care. 2000;23:1278-1283.

14. Knowler WC, Barrett-Connor E, Fowler SE, et al. Reduction in the incidence of type 2 diabetes with lifestyle intervention or metformin. N Engl J Med. 2002;346:393-403.

15. Look ARG, Wing RR. Long-term effects of a lifestyle intervention on weight and cardiovascular risk factors in individuals with type 2 diabetes mellitus: four-year results of the Look AHEAD trial. Arch Intern Med. 2010;170:1566-1575.

16. Tuomilehto J, Lindstrom J, Eriksson JG, et al. Prevention of type 2 diabetes mellitus by changes in lifestyle among subjects with impaired glucose tolerance. $N$ EnglJ Med. 2001;344:1343-1350.

17. Kaul A, Sharma J. Impact of bariatric surgery on comorbidities. Surg Clin North Am. 2011:91:1295-1312.

18. Meijer RI, van Wagensveld BA, Siegert CE, Eringa EC, Serne EH, Smulders YM. Bariatric surgery as a novel treatment for type 2 diabetes mellitus: a systematic review. Arch Surg. 2011;146:744-750.

19. Tsiros MD, Sinn N, Coates AM, Howe PR, Buckley JD. Treatment of adolescent overweight and obesity. Eur J Pediatr. 2008;167:9-16.

20. Brown T, Summerbell C. Systematic review of school-based interventions that focus on changing dietary intake and physical activity levels to prevent childhood obesity: an update to the obesity guidance produced by the National Institute for Health and Clinical Excellence. Obes Rev. 2009;10:110-141.

21. Birch LL, Ventura AK. Preventing childhood obesity: what works? Int J Obes (Lond). 2009;33(suppl 1):S74-S81.

22. Economos CD, Irish-Hauser S. Community interventions: a brief overview and their application to the obesity epidemic. J Law Med Ethics. 2007;35:131-137.

23. Unick JL, Beavers D, Jakicic JM, et al.
Effectiveness of lifestyle interventions for individuals with severe obesity and type 2 diabetes: results from the Look AHEAD trial. Diabetes Care. 2011;34:2152-2157.

24. Lecheminant JD, Kirk EP, Hall MA, et al. Impact of different levels of weight loss on blood pressure in overweight and obese women. Dis Manag. 2007;10:83-90.

25. Ilanne-Parikka P, Eriksson JG, Lindstrom J, et al. Effect of lifestyle intervention on the occurrence of metabolic syndrome and its components in the Finnish Diabetes Prevention Study. Diabetes Care. 2008;31:805-807.

26. Grunstein RR, Stenlof K, Hedner JA, Peltonen M, Karason K, Sjostrom L. Two year reduction in sleep apnea symptoms and associated diabetes incidence after weight loss in severe obesity. Sleep. 2007;30:703-710.

27. Subak LL, Wing R, West DS, et al. Weight loss to treat urinary incontinence in overweight and obese women. N Engl J Med. 2009;360:481-490.

28. Wadden TA, Stunkard AJ. Psychosocial consequences of obesity and dieting: research and clinical findings. In: Stunkard AJ, Wadden TA, eds. Obesity: Theory and Therapy. 2nd ed. New York, NY: Raven Press; 1993:163-179.

29. Gladis NM, Wadden TA, Vogt R, Foster G, Kuehnel RH, Bartlett SJ. Behavioral treatment of obese binge eaters: do they need different care? J Psychosom Res. 1998;44:375-384.

30. Foster GD, Wadden TA, Vogt RA. Body image in obese women before, during, and after weight loss treatment. Health Psychol. 1997;16:226-229.

31. Fujimoto WY, Jablonski KA, Bray GA, et al. Body size and shape changes and the risk of diabetes in the Diabetes Prevention Program. Diabetes. 2007;56:1680-1685.

32. Eriksson J, Lindstrom J, Valle T, et al. Prevention of type II diabetes in subjects with impaired glucose tolerance: the Diabetes Prevention Study (DPS) in Finland. Study design and 1-year interim report on the feasibility of the lifestyle intervention programme. Diabetologia. 1999;42:793-801.

33. Redmon JB, Bertoni AG, Connelly S, et al. Effect of the look AHEAD study intervention on medication use and related cost to treat cardiovascular disease risk factors in individuals with type 2 diabetes. Diabetes Care. 2010;33:1153-1158.

34. Wing RR, Lang W, Wadden TA, et al. Benefits of modest weight loss in improving cardiovascular risk factors in overweight and obese individuals with type 2 diabetes. Diabetes Care. 2011;34:1481-1486.

35. Klein S, Burke LE, Bray GA, et al. Clinical 
implications of obesity with specific focus on cardiovascular disease: a statement for professionals from the American Heart Association Council on Nutrition, Physical Activity, and Metabolism: endorsed by the American College of Cardiology Foundation. Circulation. 2004;110:2952-2967.

36. UK Prospective Diabetes Study 7: response of fasting plasma glucose to diet therapy in newly presenting type II diabetic patients, UKPDS Group. Metabolism. 1990;39:905-912.

37. Manco M, Mingrone G. Effects of weight loss and calorie restriction on carbohydrate metabolism. Curr Opin Clin Nutr Metab Care. 2005;8:431-439.

38. Shaw K, O'Rourke P, Del Mar C, Kenardy J. Psychological interventions for overweight or obesity. Cochrane Database Syst Rev. 2005;(2):CD003818.

39. Wadden TA, Butryn ML, Wilson C. Lifestyle modification for the management of obesity. Gastroenterology. 2007;132:2226-2238.

40. Wadden TA, Butryn ML, Byrne KJ. Efficacy of lifestyle modification for long-term weight control. Obes Res. 2004;12(suppl):151S-162S.

41. Knowler WC, Barrett-Connor E, Fowler SE, et al. Reduction in the incidence of type 2 diabetes with lifestyle intervention or metformin. N Engl J Med. 2002;346:393-403.

42. Wing RR, Phelan S. Behavioral treatment in obesity. In: Eckel RH, ed. Obesity: An Academic Basis for Clinical Evaluation and Treatment. Philadelphia, PA: Lippincott Williams \& Wilkins; 2002;415-435.

43. Wing RR. Long-term effects of a lifestyle intervention on weight and cardiovascular risk factors in individuals with type 2 diabetes mellitus: four-year results of the Look AHEAD trial. Arch Intern Med. 2010;170:1566-1575.

44. Pascale RW, Wing RR, Butler BA, Mullen M, Bononi P. Effects of a behavioral weight loss program stressing calorie restriction versus calorie plus fat restriction in obese individuals with NIDDM or a family history of diabetes. Diabetes Care. 1995;18:1241-1248.

45. Schlundt DG, Hill JO, Pope-Cordle J, Arnold D, Virts KL, Katahn M. Randomized evaluation of a low fat ad libitum carbohydrate diet for weight reduction. Int J Obes Relat Metab Disord. 1993;17:623-629.

46. Wadden TA, Stunkard AJ, Brownell KD. Very low calorie diets: their efficacy, safety, and future. Ann Intern Med. 1983;99:675-684.

47. Wing RR, Blair EH, Bononi P, Marcus MD, Watanabe R, Bergman RN. Caloric restriction per se is a significant factor in improvements in glycemic control and insulin sensitivity during weight loss in obese NIDDM patients. Diabetes Care. 1994:17:30-36.

48. Wadden TA, Foster GD, Letizia KA. Oneyear behavioral treatment of obesity: comparison of moderate and severe caloric restriction and the effects of weight maintenance therapy. J Consult Clin Psychol. 1994;62:165-171.

49. Rolls BJ, Shide DJ. The influence of dietary fat on food intake and body weight. Nutr Rev. 1992;50:283-290.

50. Tucker LA, Kano MJ. Dietary fat and body fat: a multivariate study of 205 adult females. Am J Clin Nutr. 1992;56:616-622.

51. Ma Y, Olendzki BC, Hafner AR, et al. Low-carbohydrate and high-fat intake among adult patients with poorly controlled type 2 diabetes mellitus. Nutrition. 2006;22:1129-1136.

52. Foster GD, Wyatt HR, Hill JO, et al. Weight and metabolic outcomes after 2 years on a low-carbohydrate versus low-fat diet: a randomized trial. Ann Intern Med. 2010;153:147-157.

53. Hauner H. Low-carbohydrate or low-fat diet for weight loss: which is better? [in German]. MMW Fortschr Med. 2004;146:3335,37 .

54. Wycherley TP, Brinkworth GD, Keogh JB, Noakes M, Buckley JD, Clifton PM. Longterm effects of weight loss with a very low carbohydrate and low fat diet on vascular function in overweight and obese patients. J Intern Med. 2010;267:452-461.

55. Ornish D. Weight loss with a low-carbohydrate, Mediterranean, or low-fat diet. $N$ Engl J Med. 2008;359:2170; author reply 2171-2172.

56. Samaha FF, Iqbal N, Seshadri P, et al. A low-carbohydrate as compared with a lowfat diet in severe obesity. $N$ Engl J Med. 2003;348:2074-2081.

57. Dansinger ML, Gleason JA, Griffith JL, Selker HP, Schaefer EJ. Comparison of the Atkins, Ornish, Weight Watchers, and Zone diets for weight loss and heart disease risk reduction: a randomized trial. JAMA. 2005;293:43-53.

58. Wadden TA, Frey DL. A multicenter evaluation of a proprietary weight loss program for the treatment of marked obesity: a five-year follow-up. Int J Eat Disord. 1997;22:203-212.

59. Ditschuneit HH. Do meal replacement drinks have a role in diabetes management? Nestle Nutr Workshop Ser Clin Perform Programme. 2006;11:171-179; discussion 179-181.

60. Jeffery RW, Wing RR, Thorson C, et al. Strengthening behavioral interventions for weight loss: a randomized trial of food provision and monetary incentives. $J$
Consult Clin Psychol. 1993;61:1038-1045.

61. Wing RR, Jeffery RW, Burton LR, Thorson C, Nissinoff KS, Baxter JE. Food provision vs structured meal plans in the behavioral treatment of obesity. Int J Obes Relat Metab Disord. 1996;20:56-62.

62. Donnelly JE, Blair SN, Jakicic JM, et al. American College of Sports Medicine Position Stand: appropriate physical activity intervention strategies for weight loss and prevention of weight regain for adults. Med Sci Sports Exerc. 2009;41:459-471.

63. Wing RR, Venditti E, Jakicic JM, Polley BA, Lang W. Lifestyle intervention in overweight individuals with a family history of diabetes. Diabetes Care. 1998;21:350-359.

64. Donnelly JE, Kirk EP, Jacobsen DJ, Hill JO, Sullivan DK, Johnson SL. Effects of 16 mo of verified, supervised aerobic exercise on macronutrient intake in overweight men and women: the Midwest Exercise Trial. Am J Clin Nutr. 2003;78:950-956.

65. Donnelly JE, Smith BK. Is exercise effective for weight loss with ad libitum diet? Energy balance, compensation, and gender differences. Exerc Sport Sci Rev. 2005;33:169-174.

66. Potteiger JA, Jacobsen DJ, Donnelly JE, Hill JO; Midwest Exercise Trial. Glucose and insulin responses following 16 months of exercise training in overweight adults: the Midwest Exercise Trial. Metabolism. 2003;52:1175-1181.

67. Brooks GA, Butte NF, Rand WM, Flatt JP, Caballero B. Chronicle of the Institute of Medicine physical activity recommendation: how a physical activity recommendation came to be among dietary recommendations. Am J Clin Nutr. 2004;79:921S-930S.

68. Catenacci VA, Ogden LG, Stuht J, et al. Physical activity patterns in the National Weight Control Registry. Obesity (Silver Spring). 2008;16:153-161.

69. Friedlander AL, Casazza GA, Horning MA, Huie MJ, Brooks GA. Training-induced alterations of glucose flux in men. $J$ Appl Physiol. 1997;82:1360-1369.

70. Zarins ZA, Wallis GA, Faghihnia N, et al. Effects of endurance training on cardiorespiratory fitness and substrate partitioning in postmenopausal women. Metabolism. 2009;58:1338-1346.

71. Hagobian TA, Sharoff CG, Stephens BR, et al. Effects of exercise on energyregulating hormones and appetite in men and women. Am J Physiol Regul Integr Comp Physiol. 2009;296:R233-242.

72. Malin SK, Gerber R, Chipkin SR, Braun B. Independent and combined effects of exercise training and metformin on insulin sensitivity in individuals with prediabetes. Diabetes Care. 2012:35:131-136. 
73. Sawada SS, Lee IM, Naito H, et al. Longterm trends in cardiorespiratory fitness and the incidence of type 2 diabetes. Diabetes Care. 2010;33:1353-1357.

74. Sieverdes JC, Sui X, Lee DC, et al. Physical activity, cardiorespiratory fitness and the incidence of type 2 diabetes in a prospective study of men. Br J Sports Med. 2010;44:238-244.

75. Lee DC, Sui X, Artero EG, et al. Long-term effects of changes in cardiorespiratory fitness and body mass index on all-cause and cardiovascular disease mortality in men: the aerobics center longitudinal study. Circulation. 2011;124:2483-2490.

76. Gaesser GA, Angadi SS, Sawyer BJ. Exercise and diet, independent of weight loss, improve cardiometabolic risk profile in overweight and obese individuals. Phys Sportsmed. 2011;39:87-97.

77. Physical Activity Guidelines Advisory Committee report, 2008. To the Secretary of Health and Human Services. Part A: executive summary. Nutr Rev. 2009;67:114-120

78. Garber CE, Blissmer B, Deschenes MR, et al. American College of Sports Medicine position stand. Quantity and quality of exercise for developing and maintaining cardiorespiratory, musculoskeletal, and neuromotor fitness in apparently healthy adults: guidance for prescribing exercise. Med Sci Sports Exerc. 2011;43: 1334-1359.

79. Haskell WL, Lee IM, Pate RR, et al. Physical activity and public health: updated recommendation for adults from the American College of Sports Medicine and the American Heart Association. Med Sci Sports Exerc. 2007;39:1423-1434.

80. Haskell WL, Lee IM, Pate RR, et al. Physical activity and public health: updated recommendation for adults from the American College of Sports Medicine and the American Heart Association. Circulation. 2007:116:1081-1093.

81. Hansen D, Dendale P, Berger J, van Loon LJ, Meeusen R. The effects of exercise training on fat-mass loss in obese patients during energy intake restriction. Sports Med. 2007;37:31-46.

82. Holten MK, Zacho M, Gaster M, Juel C, Wojtaszewski JF, Dela F. Strength training increases insulin-mediated glucose uptake, GLUT4 content, and insulin signaling in skeletal muscle in patients with type 2 diabetes. Diabetes. 2004;53:294-305.

83. Jakicic JM, Winters C, Lang W, Wing RR. Effects of intermittent exercise and use of home exercise equipment on adherence, weight loss, and fitness in overweight women: a randomized trial. JAMA. 1999;282:1554-1560.

84. Jeffery RW, Wing RR, Sherwood NE, Tate DF. Physical activity and weight loss: does prescribing higher physical activity goals improve outcome? Am J Clin Nutr. 2003; 78:684-689.

85. Tate DF, Jeffery RW, Sherwood NE, Wing RR. Long-term weight losses associated with prescription of higher physical activity goals: are higher levels of physical activity protective against weight regain? Am J Clin Nutr. 2007;85:954-959.

86. Jakicic JM, Wing RR, Butler BA, Robertson RJ. Prescribing exercise in multiple short bouts versus one continuous bout: effects on adherence, cardiorespiratory fitness, and weight loss in overweight women. Int J Obes Relat Metab Disord. 1995;19:893-901.

87. Jakicic JM, Wing RR, Butler BA, Jeffery RW. The relationship between presence of exercise equipment in the home and physical activity level. Am J Health Promot. 1997;11:363-365.

88. Raynor DA, Coleman KJ, Epstein LH. Effects of proximity on the choice to be physically active or sedentary. Res $Q$ Exerc Sport. 1998;69:99-103.

89. Perri MG, Martin AD, Leermakers EA, Sears SF, Notelovitz M. Effects of groupversus home-based exercise in the treatment of obesity. J Consult Clin Psychol. 1997:65:278-285.

90. Wadden TA, Osei S. The Treatment of Obesity: An Overview. In: Wadden TA, Stunkard AJ, ed. Handbook of Obesity Treatment. New York, NY: The Guilford Press; page 229, 2002.

91. Baker RC, Kirschenbaum DS. Selfmonitoring may be necessary for successful weight control. Behav Ther. 1993;24:377-394.

92. Wadden TA, Letizia KA. Predictors of attrition and weight loss in patients treated by moderate and severe caloric restriction. In: Wadden TA, VanItallie TB, eds. Treatment of the Seriously Obese Patient. New York, NY: Guilford Press; 1992:383-410.

93. Vanwormer JJ, French SA, Pereira MA, Welsh EM. The impact of regular selfweighing on weight management: a systematic literature review. Int J Behav Nutr Phys Act. 2008;5:54.

94. Lombard CB, Deeks AA, Teede HJ. A systematic review of interventions aimed at the prevention of weight gain in adults. Public Health Nutr. 2009;12:2236-2246.

95. Linde JA, Jeffery RW, French SA, Pronk NP, Boyle RG. Self-weighing in weight gain prevention and weight loss trials. Ann Behav Med. 2005;30:210-216.

96. VanWormer JJ, Martinez AM, Martinson BC, et al. Self-weighing promotes weight loss for obese adults. Am J Prev Med. 2009;36:70-73.

97. Wing RR, Tate DF, Gorin AA, Raynor HA, Fava JL, Machan J. STOP regain: are there negative effects of daily weighing? J Consult Clin Psychol. 2007;75:652-656.

98. Burke LE, Conroy MB, Sereika SM, et al. The effect of electronic self-monitoring on weight loss and dietary intake: a randomized behavioral weight loss trial. Obesity (Silver Spring). 2011;19:338-344.

99. Harvey-Berino J, Pintauro S, Buzzell P, Gold EC. Effect of Internet support on the long-term maintenance of weight loss. Obes Res. 2004;12:320-329.

100. Marlatt GA, Gordon JR. Relapse Prevention: Maintenance Strategies in Addictive Behavior Change. New York, NY: Guilford; 1985.

101. Perri MG, Nezu AM, McKelvey WF, Shermer RL, Renjilian DA, Viegener BJ. Relapse prevention training and problemsolving therapy in the long-term management of obesity. J Consult Clin Psychol. 2001;69:722-726.

102. Perri MG, Shapiro RM, Ludwig WW, Twentyman CT, McAdoo WG. Maintenance strategies for the treatment of obesity: an evaluation of relapse prevention training and posttreatment contact by mail and telephone. J Consult Clin Psychol. 1984;52:404-413.

103. Black DR, Gleser LJ, Kooyers KJ. A metaanalytic evaluation of couples weightloss programs. Health Psychol. 1990;9: 330-347.

104. Wing R, Jeffery R. Benefits of recruiting participants with friends and increasing social support for weight loss and maintenance. J Consult Clin Psychol. 1999;67:132-138.

105. McLean N, Griffin S, Toney K, Hardeman W. Family involvement in weight control, weight maintenance and weight-loss interventions: a systematic review of randomised trials. Int J Obes Relat Metab Disord. 2003;27:987-1005.

106. Gorin AA, Le Grange D, Stone AA. Effectiveness of spouse involvement in cognitive behavioral therapy for binge eating disorder. Int J Eat Disord. 2003;33:421-433.

107. Wing RR, Blair E, Marcus M, Epstein LH, Harvey J. Year-long weight loss treatment for obese patients with type II diabetes: does including an intermittent very-lowcalorie diet improve outcome? Am J Med. 1994:97:354-362.

108. Perri MG, McAllister DA, Gange JJ, Jordan RC, McAdoo G, Nezu AM. Effects of four maintenance programs on the longterm management of obesity. J Consult Clin Psychol. 1988;56:529-534.

109. Renjilian DA, Perri MG, Nezu AM, McKelvey WF, Shermer RL, Anton SD. Individual versus group therapy for obesity: effects of matching participants to their treatment preferences. J Consult Clin Psychol. 2001;69:717-721. 
110. Knowler WC, Hamman RF, Edelstein SL, et al. Prevention of type 2 diabetes with troglitazone in the Diabetes Prevention Program. Diabetes. 2005;54:1150-1156.

111. Hamman RF, Wing RR, Edelstein SL, et al. Effect of weight loss with lifestyle intervention on risk of diabetes. Diabetes Care. 2006;29:2102-2107.

112. Look ARG, Wadden TA, West DS, et al. The Look AHEAD study: a description of the lifestyle intervention and the evidence supporting it. Obesity (Silver Spring). 2006;14:737-752.

113. Ryan DH, Espeland MA, Foster GD, et al. Look AHEAD (Action for Health in Diabetes): design and methods for a clinical trial of weight loss for the prevention of cardiovascular disease in type 2 diabetes. Control Clin Trials. 2003;24:610-628.

114. Wadden TA, Neiberg RH, Wing RR, et al. Four-year weight losses in the Look AHEAD study: factors associated with long-term success. Obesity (Silver Spring). 2011;19:1987-1998.

115. Brinkworth GD, Noakes M, Parker B, Foster P, Clifton PM. Long-term effects of advice to consume a high-protein, low-fat diet, rather than a conventional weight-loss diet, in obese adults with type 2 diabetes: one-year follow-up of a randomised trial. Diabetologia. 2004;47:1677-1686.

116. Hollander PA, Elbein SC, Hirsch IB, et al. Role of orlistat in the treatment of obese patients with type 2 diabetes: a 1-year randomized double-blind study. Diabetes Care. 1998;21:1288-1294.

117. Li Z, Hong K, Saltsman P, et al. Longterm efficacy of soy-based meal replacements vs an individualized diet plan in obese type II DM patients: relative effects on weight loss, metabolic parameters, and C-reactive protein. Eur J Clin Nutr. 2005;59:411-418.

118. Redmon JB, Reck KP, Raatz SK, et al. Twoyear outcome of a combination of weight loss therapies for type 2 diabetes. Diabetes Care. 2005;28:1311-1315.

119. Wolf AM, Conaway MR, Crowther JQ, et al. Translating lifestyle intervention to practice in obese patients with type 2 diabetes: Improving Control with Activity and Nutrition (ICAN) study. Diabetes Care. 2004;27:1570-1576.

120. Stunkard A, McLaren-Hume M. The results of treatment for obesity: a review of the literature and report of a series. AMA Arch Intern Med. 1959;103:79-85.

121. Vogels N, Diepvens K, WesterterpPlantenga MS. Predictors of longterm weight maintenance. Obes Res 2005;13:2162-2168.

122. Wadden TA, Foster GD, Letizia KA. Response of obese binge eaters to treatment by behavior therapy combined with very low calorie diet. J Consult Clin Psychol. 1992;60:808-811.

123. Leibel RL, Rosenbaum M, Hirsch J. Changes in energy expenditure resulting from altered body weight. $N$ Engl J Med. 1995;332:621-628.

124. Cummings DE, Weigle DS, Frayo RS, et al Plasma ghrelin levels after diet-induced weight loss or gastric bypass surgery. $N$ Engl J Med. 2002;346:1623-1630.

125. Sumithran P, Prendergast LA, Delbridge E, et al. Long-term persistence of hormonal adaptations to weight loss. $N$ Engl J Med. 2011;365:1597-1604.

126. Wadden TA. What characterizes successful weight maintainers? In: Allison DB, Pi-Sunyer Z, eds. Obesity Treatment. New York, NY: Plenum; 1995:103-111.

127. Hill JO, Wyatt HR. Relapse in obesity treatment: biology or behavior? Am J Clin Nutr. 1999:69:1064-1065.

128. Phelan S, Wing RR, Loria CM, Kim Y, Lewis CE. Prevalence and predictors of weight-loss maintenance in a biracial cohort: results from the coronary artery risk development in young adults study. Am J Prev Med. 2010;39:546-554.

129. Weiss EC, Galuska DA, Kettel Khan L, Gillespie C, Serdula MK. Weight regain in U.S. adults who experienced substantial weight loss, 1999-2002. Am J Prev Med. 2007;33:34-40.

130. Klem ML, Wing RR, McGuire MT, Seagle HM Hill JO. A descriptive study of individuals successful at long-term maintenance of substantial weight loss. Am J Clin Nutr. 1997;66:239-246.

131. Butryn ML, Phelan S, Hill JO, Wing RR. Consistent self-monitoring of weight: a key component of successful weight loss maintenance. Obesity (Silver Spring). 2007;15:3091-3096.

132. Gorin AA, Phelan S, Wing RR, Hill JO. Promoting long-term weight control: does dieting consistency matter? Int J Obes Relat Metab Disord. 2004;28:278-281.

133. Raynor DA, Phelan S, Hill JO, Wing RR. Television viewing and long-term weight maintenance: results from the National Weight Control Registry. Obesity (Silver Spring). 2006;14:1816-1824.

134. Phelan S, Liu T, Gorin A, et al. What distinguishes weight-loss maintainers from the treatment-seeking obese? Analysis of environmental, behavioral, and psychosocial variables in diverse populations. Ann Behav Med. 2009;38:94-104.

135. Tate DF, Wing RR, Winett RA. Using Internet technology to deliver a behavioral weight loss program. JAMA. 2001;285:1172-1177.

136. Svetkey LP, Stevens VJ, Brantley PJ, et al. Comparison of strategies for sustaining weight loss: the weight loss maintenance randomized controlled trial. JAMA. 2008;299:1139-1148.

137. Wing RR, Tate DF, Gorin A, Raynor HA, Fava JL. A self-regulation program for maintenance of weight loss. $\mathrm{NEnglJ}$ Med. 2006;346:393-403

138. Harvey-Berino J, Krukowski RA, Buzzell P, Ogden D, Skelly J, West DS. The accuracy of weight reported in a Web-based obesity treatment program. Telemed J E Health. 2011;17:696-699.

139. Tate DF, Jackvony EH, Wing RR. Effects of Internet behavioral counseling on weight loss in adults at risk for type 2 diabetes: a randomized trial. JAMA. 2003;289:1833-1836.

140. Tate DF, Jackvony EH, Wing RR. A randomized trial comparing human e-mail counseling, computer-automated tailored counseling, and no counseling in an Internet weight loss program. Arch Intern Med. 2006;166:1620-1625.

141. Thomas D, Vydelingum V, Lawrence J. E-mail contact as an effective strategy in the maintenance of weight loss in adults. $J$ Hum Nutr Diet. 2011;24:32-38.

142. Turner-McGrievy G, Tate D. Tweets, Apps, and Pods: results of the 6-month mobile pounds off digitally (mobile POD) randomized weight-loss intervention among adults. J Med Internet Res. 2011;13:e120.

143. Krukowski RA, Tilford JM, Harvey-Berino J, West DS. Comparing behavioral weight loss modalities: incremental costeffectiveness of an internet-based versus an in-person condition. Obesity (Silver Spring). 2011:19:1629-1635.

144. Patrick K, Raab F, Adams MA, et al. A text message-based intervention for weight loss: randomized controlled trial. J Med Internet Res. 2009;11:e1.

145. Coons MJ, Roehrig M, Spring B. The potential of virtual reality technologies to improve adherence to weight loss behaviors. J Diabetes Sci Technol. 2011;5:340-344.

146. Gay G, Pollak J, Adams P, Leonard JP. Pilot study of Aurora, a social, mobilephone-based emotion sharing and recording system. J Diabetes Sci Technol. 2011;5:325-332.

147. Skip Rizzo A, Lange B, Suma EA, Bolas M. Virtual reality and interactive digital game technology: new tools to address obesity and diabetes. J Diabetes Sci Technol. 2011;5:256-264.

148. Lyznicki JM, Young DC, Riggs JA, Davis RM. Obesity: assessment and management in primary care. Am Fam Physician. 2001;63:2185-2196.

149. Tsai AG, Wadden TA. Treatment of obesity in primary care practice in the United States: a systematic review. J Gen Intern Med. 2009;24:1073-1079. 
150. Christian JG, Bessesen DH, Byers TE, Christian KK, Goldstein MG, Bock BC. Clinic-based support to help overweight patients with type 2 diabetes increase physical activity and lose weight. Arch Intern Med. 2008;168:141-146.

151. Christian JG, Byers TE, Christian KK, et al. A computer support program that helps clinicians provide patients with metabolic syndrome tailored counseling to promote weight loss. J Am Diet Assoc. 2011;111:75-83.

152. Galuska DA, Will JC, Serdula MK, Ford ES. Are health care professionals advising obese patients to lose weight? JAMA. 1999;282:1576-1578.

153. Rao G, Burke LE, Spring BJ, et al. New and emerging weight management strategies for busy ambulatory settings: a scientific statement from the American Heart Association endorsed by the Society of Behavioral Medicine. Circulation. 2011;124:1182-1203.

154. Clinical guidelines on the identification, evaluation, and treatment of overweight and obesity in adults: the evidence report. National Institutes of Health. Obes Res. 1998;6:51S-210S.

155. Anderson DA, Wadden TA. Treating the obese patient: suggestions for primary care practice. Arch Fam Med. 1999;8:159-167.

156. World Health Organization. Obesity: Preventing and Managing the Global Epidemic. Geneva, Switzerland: WHO; 1998.

157. Bray GA. Contemporary Diagnosis and Management of Obesity. Newtown, PA: Handbooks in Health Care; 1998.

158. McTigue KM, Harris R, Hemphill B, et al. Screening and interventions for obesity in adults: summary of the evidence for the U.S. Preventive Services Task Force. Ann Intern Med. 2003;139:933-949.
159. Wadden TA, Didie E. What's in a name? Patients' preferred terms for describing obesity. Obes Res. 2003;11:1140-1146.

160. Heshka S, Anderson JW, Atkinson RL, et al. Weight loss with self-help compared with a structured commercial program: a randomized trial. JAMA. 2003;289:1792-1798.

161. Tsai AG, Wadden TA. Systematic review: an evaluation of major commercial weight loss programs in the United States. Ann Intern Med. 2005;142:56-66.

162. Jelalian E, Hart CN, Rhee K. Treatment of pediatric obesity. Med Health R I. 2009;92:48-49.

163. Phelan S. Pregnancy: a "teachable moment" for weight control and obesity prevention. Am J Obstet Gynecol. 2010;202:e131-e138.

164. Linne $Y$, Barkeling B, Rossner S. Natural course of gestational diabetes mellitus: long term follow up of women in the SPAWN study. BJOG. 2002;109:1227-1231.

165. O'Sullivean JB. Subsequent morbidity among gestational diabetic women. In: Sutherland HW, Stowers JM, eds. Carbohydrate Metabolism in Pregnancy and the Newborn. Edingburgh, UK: Churchill Livingstone; 1984:174-180.

166. Guelinckx I, Devlieger R, Beckers K, Vansant G. Maternal obesity: pregnancy complications, gestational weight gain and nutrition. Obes Rev. 2008;9:140-150.

167. Gunderson EP, Lewis CE, Tsai AL, et al. A 20-year prospective study of childbearing and incidence of diabetes in young women, controlling for glycemia before conception: the Coronary Artery Risk Development in Young Adults (CARDIA) Study. Diabetes. 2007;56:2990-2996.

168. Pettitt DJ, Narayan KM, Hanson RL, Knowler WC. Incidence of diabetes mellitus in women following impaired glucose tolerance in pregnancy is lower than following impaired glucose tolerance in the non-pregnant state. Diabetologia. 1996;39:1334-1337.

169. Peters RK, Kjos SL, Xiang A, Buchanan TA. Long-term diabetogenic effect of single pregnancy in women with previous gestational diabetes mellitus. Lancet. 1996;347:227-230.

170. Pole JD, Dodds LA. Maternal outcomes associated with weight change between pregnancies. Can J Public Health. 1999;90:233-236.

171. Villamor E, Cnattingius S. Interpregnancy weight change and risk of adverse pregnancy outcomes: a population-based study. Lancet. 2006;368:1164-1170.

172. Nohira T, Kim S, Nakai H, Okabe K, Yoneyama K. Recurrence of gestational diabetes mellitus: rates and risk factors from initial GDM and one abnormal GTT value. Diabetes Res Clin Pract. 2006;71:75-81.

173. Kral JG, Biron S, Simard S, et al. Large maternal weight loss from obesity surgery prevents transmission of obesity to children who were followed for 2 to 18 years. Pediatrics. 2006;118:e1644-e1649.

174. Olson CM, Strawderman MS, Reed RG. Efficacy of an intervention to prevent excessive gestational weight gain. Am J Obstet Gynecol. 2004;191:530-536.

175. Polley BA, Wing RR, Sims CJ. Randomized controlled trial to prevent excessive weight gain in pregnant women. Int J Obes Relat Metab Disord. 2002;26:1494-1502.

176. Phelan S, Phipps MG, Abrams B, Darroch F, Schaffner A, Wing RR. Randomized trial of a behavioral intervention to prevent excessive gestational weight gain: the Fit for Delivery Study. Am J Clin Nutr. 2011;93:772-779. 